https://doi.org/10.15407/ujpe63.12.1088

V.I. BOICHUK, R.YA. LESHKO, D.S. KARPYN

Physics Department, Ivan Franko Drohobych State Pedagogical University

(3, Stryiska Str., Lviv region, Drohobych 82100, Ukraine)

\title{
THE EFFECT OF SHALLOW
}

IMPURITIES ON THE LIGHT ABSORPTION BY THE NANOCRYSTALS CdS

\begin{abstract}
The energy of quantum transitions of exciton-impurity states in a heterosystem with nanocrystals is calculated. The absorption spectra associated with the indicated transitions are analyzed. It is qualitatively shown that broad luminescence bands in the red region are related to the impurity acceptor states, and the high narrow ones in the violet region to pure excitonic states and excitonic states interacting with the ion of a donor. The satisfactory quantitative agreement of our calculations with experimental data for high energy luminescence bands is obtained.

Ke ywords: acceptor and donor imputities, exciton, light absorption coefficient, nanocrystal.
\end{abstract}

\section{Introduction}

Important tasks of scientists and technologists in materials science are the search for new materials that can be applied in nanoelectronics. The most productive way in this direction is the use of heterosystems with various nanoobjects: quantum dots (QDs), quantum wires (QDs), quantum wells (QWs), and their combination. Based on these systems, there is a significant number of devices, whose main characteristic is the low power consumption and high performance.

The main task of physicists is to develop effective models for forecasting and managing the properties of QD, detecting and fixing these properties, as well as the development of a methodology that will allow one to get the assigned high-quality objects with predefined characteristics.

Today, high-quality QDs can be produced, but there is no guarantee of the absence of various defects in them. In a single nanocrystal, at least one impurity atom can be present. Moreover, the impurities can

(C) V.I. BOICHUK, R.YA. LESHKO, D.S. KARPYN, 2018

1088 passivate the torn ties on the QD surface. In addition, the impurities can be purposefully injected into a nanoobject by the doping. Therefore, the impurities may be in the QD and affect its properties. In this connection, there are a number of theoretical works [1-9], in which the energy spectra of donors and acceptors are determined as functions of the nanocrystal parameters.

The most informative and relatively simple methods that give a possibility to study the electronic structure of QDs in practice are experiments dealing with the photoluminescence and absorption of light. These data are the basis, on which we can test the theoretical models relating to the energy structure of nanocrystals and to the linear or nonlinear absorption of electromagnetic waves.

There is a significant number of experimental works on the luminescence and the absorption of electromagnetic waves by nanocrystals [10-15]. The authors of these and other papers obtained the dependences of the luminescence intensity on the average size of nanocrystals and the wavelength. Many researchers are attracted by the heterostructures of QD CdS. It

ISSN 2071-0186. Ukr. J. Phys. 2018. Vol. 63, No. 12 
turned out that they can be used in biological indicators, in light-emitting diodes with a high coefficient of usefulness actions, etc.

The aims of this work are

- calculation of the electron transition energy into the exciton and exciton-donor states and the determination of the light absorption coefficient connected with those transitions;

- analysis of obtained theoretical results and their comparison with experimental data on the photoluminescence in the visible spectral range for the heterosystem with nanocrystals $C d S$.

\section{Formulation of the Problem. The Solution of the Schrödinger Equation for an Exciton and Exciton-Impurity Complexes in the QD}

The heterosystem with a spherical semiconductor nanocrystal with radius $a$, which is placed in a dielectric matrix, is considered. Let the size of a nanocrystal be such that, to solve the Schrödinger equation for electrons or holes, we can use the effective mass method. We suppose that the effective masses of quasiparticles are isotropic in each component of the heterosystem. The electron and heavy hole effective masses in the nanocrystal are $m_{e ; 1}, m_{h ; 1}$; and $m_{e ; 2}, m_{h ; 2}$ in the matrix, respectively. The dielectric permittivity of the QD and matrix are $\varepsilon_{1}$ and $\varepsilon_{2}$, respectively. We suppose that, at the center of the QD, charged or neutral impurities of the donor or acceptor type can be present. Those impurities can cause the formation of impurity-exciton complexes of various kinds: $D^{+}-X$ (positive charged ion of the donor impurity $D^{+}$and exciton $X$ ); $A^{-}-X$ (negative charged ion of the acceptor impurity $A^{-}$and exciton); $D^{0}-X$ (neutral donor impurity $D^{0}$ and exciton $X$ ); and $A^{0}-X$ (neutral acceptor impurity and exciton). Those complexes are manifested in the optical spectra.

The Hamiltonian of electrons (holes) for the complexes $D^{+}-X$ and $A^{-}-X$ (in the atom system of units) takes the form

$$
\hat{H}_{\left\{\begin{array}{l}
D^{+}-X \\
A^{-}-X
\end{array}\right\}}=\hat{H}_{\left\{\begin{array}{l}
D \\
A
\end{array}\right\}}+\hat{H}_{\left\{\begin{array}{l}
h \\
e
\end{array}\right.}-\frac{1}{\varepsilon\left|\mathbf{r}_{e}-\mathbf{r}_{h}\right|}+\frac{1}{\varepsilon r_{\left\{\begin{array}{l}
h \\
e
\end{array}\right\}}},
$$

where $\varepsilon=\left(\varepsilon_{1}+\varepsilon_{2}\right) / 2$ (Table),

$\hat{H}_{\left\{\begin{array}{l}D \\ A\}\end{array}\right.}=-\frac{1}{2} \nabla \frac{1}{m_{\left\{\begin{array}{l}e \\ h\end{array}\right.}} \nabla-\frac{1}{\varepsilon r_{\left\{\begin{array}{l}e \\ h\end{array}\right.}}+U_{\left\{\begin{array}{l}e \\ h\end{array}\right\}}\left(r_{\left\{\begin{array}{l}e \\ h\end{array}\right\}}\right)$ is the Hamiltonian of donors or acceptors,

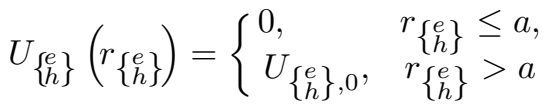

is the confinement potential,

$\hat{H}_{\left\{\begin{array}{l}h \\ e\end{array}\right.}=-\frac{1}{2} \nabla \frac{1}{m_{\left\{\begin{array}{l}h \\ e\end{array}\right.}} \nabla+U_{\left\{\begin{array}{l}h \\ e\end{array}\right\}}\left(r_{\left\{\begin{array}{l}h \\ e\end{array}\right\}}\right)$

is the Hamiltonian of one hole or electron. The Schrödinger equation with Hamiltonian (1) is solved by the variational method. The trial variational wave function is chosen as

$$
\begin{aligned}
& \psi_{\left\{\begin{array}{l}
D^{+}-X \\
A^{-}-X
\end{array}\right\}}\left(\mathbf{r}_{\left\{\begin{array}{l}
h \\
e
\end{array}\right\}}, \mathbf{r}_{\left\{\begin{array}{l}
e \\
h\}
\end{array}\right.}\right)=C_{\left\{\begin{array}{l}
D^{+}-X \\
A^{-}-X
\end{array}\right\}} \psi_{\left\{\begin{array}{l}
D \\
A
\end{array}\right\}}\left(\mathbf{r}_{\left\{\begin{array}{l}
e \\
h
\end{array}\right.}\right) \times \\
& \times \psi_{\left\{\begin{array}{l}
h \\
e
\end{array}\right.}\left(\mathbf{r}_{\left\{\begin{array}{l}
h \\
e
\end{array}\right.}\right) \exp \left[-\alpha_{\left\{\begin{array}{l}
D^{+}-X \\
A^{-}-X
\end{array}\right.}\left|\mathbf{r}_{e}-\mathbf{r}_{h}\right|\right],
\end{aligned}
$$

where $C_{\left\{\begin{array}{l}D^{+}-X \\ A^{-}-X\end{array}\right\}}$ is the normalization constant, $\psi_{\left\{\begin{array}{l}D \\ A\end{array}\right\}}$ and $\psi_{\left\{\begin{array}{l}h \\ e\end{array}\right\}}$ are exact solutions of the Schrödinger equations

$\hat{H}_{\left\{\begin{array}{l}D\} \\ A\}\end{array}\right.} \psi_{\left\{\begin{array}{l}D \\ A\end{array}\right\}}\left(\mathbf{r}_{\left\{\begin{array}{l}e \\ h\end{array}\right\}}\right)=E_{\left\{\begin{array}{l}e \\ h\end{array}\right.} \psi_{\left\{\begin{array}{l}D\} \\ A\end{array}\right.}\left(\mathbf{r}_{\left\{\begin{array}{l}e \\ h\end{array}\right.}\right)$,

$\hat{H}_{\left\{\begin{array}{l}h \\ e\end{array}\right.} \psi_{\left\{\begin{array}{l}h \\ e\end{array}\right\}}\left(\mathbf{r}_{\left\{\begin{array}{l}h \\ e\end{array}\right\}}\right)=E_{\left\{\begin{array}{l}h \\ e\end{array}\right\}} \psi_{\left\{\begin{array}{l}h \\ e\end{array}\right.}\left(\mathbf{r}_{\left\{\begin{array}{l}h \\ e\end{array}\right.}\right)$,

The solutions of Eq. (6) are expressed as the products of spherical functions and Coulomb or Whittaker functions $[2-4,7]$, and the solutions of Eq. (7) are the products of spherical functions and Bessel functions.

According to the variational Ritz method, the minimized functional is equal to the ground-state energy of each exciton-impurity complex.

The electron (hole) Hamiltonians of the heterosystem with the impurity complexes $D^{0}-X$ and $A^{0}-X$ can be written as

$$
\begin{aligned}
& \hat{H}_{\left\{\begin{array}{l}
D^{0}-X \\
A^{0}-X
\end{array}\right\}}=\hat{H}_{\left\{\begin{array}{l}
\left.D^{0}\right\}, 1 \\
\left.A^{0}\right\}
\end{array}\right.}+\hat{H}_{\left\{\begin{array}{l}
\left.D^{0}\right\}, 2 \\
\left.A^{0}\right\}
\end{array}\right.}+\hat{H}_{\left\{\begin{array}{l}
h \\
e
\end{array}\right.}- \\
& -\frac{1}{\varepsilon\left|\mathbf{r}_{\left\{\begin{array}{l}
e \\
h
\end{array}, 1\right.}-\mathbf{r}_{\left\{\begin{array}{l}
h \\
e
\end{array}\right\}}\right|}-\frac{1}{\varepsilon\left|\mathbf{r}_{\left\{\begin{array}{l}
e \\
h
\end{array}, 2\right.}-\mathbf{r}_{\left\{\begin{array}{l}
h \\
e
\end{array}\right\}}\right|}+\frac{1}{\varepsilon r_{\left\{\begin{array}{l}
h \\
e
\end{array}\right\}}},
\end{aligned}
$$

where

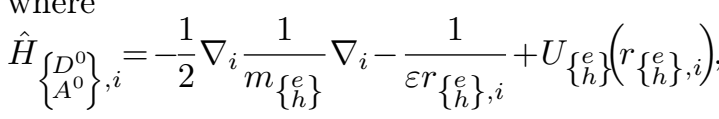

$i=1,2$, and $\hat{H}_{\left\{\begin{array}{l}h \\ e\end{array}\right\}}$ is expressed by (4). 


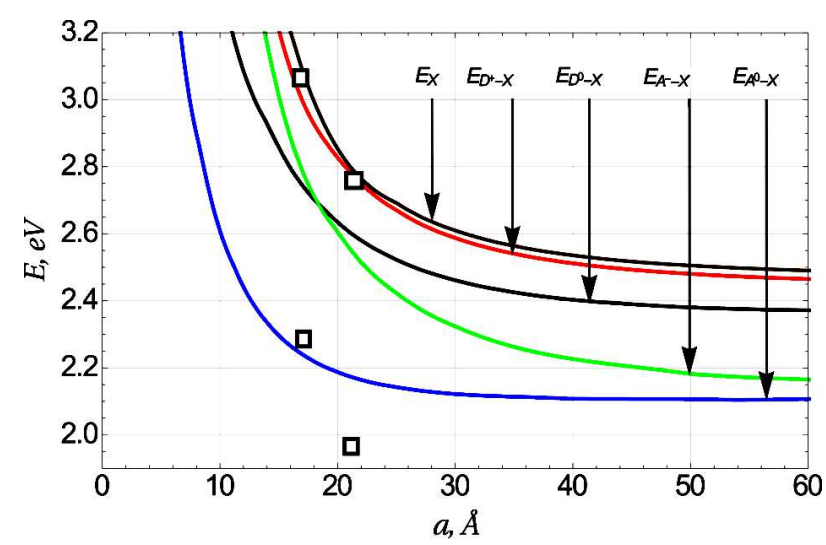

Fig. 1. Energies of the exciton and the exciton-impurity complexes in a QD. The squares represent experimentally defined $[10,13]$ energies of quantum transitions of CdS nanocrystals with average radii of 17 and $21.5 \AA$

\section{Crystal parameters}

\begin{tabular}{|l|c|c|c|c|c|}
\hline Crystal & $m_{e}$ & $m_{h}$ & $\varepsilon$ & $U_{0, e}, \mathrm{eV}$ & $U_{0, h}, \mathrm{eV}$ \\
\hline $\mathrm{CdS}$ & 0.2 & 0.74 & 5.5 & 2.70 & 3.42 \\
$\mathrm{SiO}_{2}$ & 1.0 & 1.00 & 3.9 & - & - \\
\hline
\end{tabular}

The Schrödinger equation with Hamiltonian (8) is also solved by the Ritz variational method. The trial wave function of the ground state is

$$
\begin{aligned}
& \psi_{\left\{\begin{array}{l}
D^{0}-X \\
A^{0}-X
\end{array}\right\}}\left(\mathbf{r}_{\left\{\begin{array}{l}
h \\
e
\end{array}\right\}}, \mathbf{r}_{\left\{\begin{array}{l}
e \\
h
\end{array}\right\}, 1}, \mathbf{r}_{\left\{\begin{array}{l}
e \\
h
\end{array}, 2\right.}\right)=C_{\left\{\begin{array}{l}
D^{0}-X \\
A^{0}-X
\end{array}\right.} \times \\
& \times \psi_{\left\{\begin{array}{l}
D^{0} \\
\left.A^{0}\right\}, 1
\end{array}\right.}\left(\mathbf{r}_{\left\{\begin{array}{l}
e \\
h
\end{array}, 1,1\right.}\right) \psi_{\left\{\begin{array}{l}
D\}, 2 \\
A\},
\end{array}\right.}\left(\mathbf{r}_{\left\{\begin{array}{l}
e \\
h
\end{array}, 2\right.}\right) \psi_{\left\{\begin{array}{l}
h \\
e
\end{array}\right\}}\left(\mathbf{r}_{\left\{\begin{array}{c}
h \\
e
\end{array}\right\}}\right) \times
\end{aligned}
$$

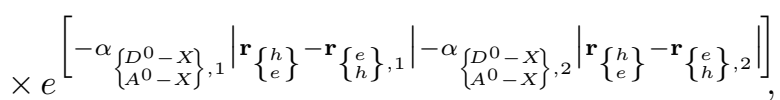

where $\psi_{\left\{D^{0}\right\}}\left(\mathbf{r}_{\left\{\begin{array}{l}e \\ h\end{array}, i\right.}\right)$ and $\psi_{\left\{\begin{array}{l}h \\ e\end{array}\right\}}\left(\mathbf{r}_{\left\{\begin{array}{l}h \\ e\end{array}\right\}}\right)$ are exact solutions of Eqs. (6) and (7), which concern with the electron and hole ground states, $\alpha_{\left\{\begin{array}{l}D^{0}-X \\ A^{0}-X\end{array}, 1,\right.}$ and $\alpha\left\{\begin{array}{l}D^{0}-X \\ \left.A^{0}-X\right\}, 2\end{array}\right.$ are variational parameters.

If there are no impurities or their influence is insignificant in the QD, then the "pure" exciton states may occur in the heterosystem. In this case, the Hamiltonian of the system has the form:

$\hat{H}_{X}=\hat{H}_{e}+\hat{H}_{h}-\frac{1}{\varepsilon\left|\mathbf{r}_{e}-\mathbf{r}_{h}\right|}$, where $\hat{H}_{e}$ and $\hat{H}_{h}$ are defined by (4), and the variational wave function for the ground state is chosen as

$\psi_{X}\left(\mathbf{r}_{e}, \mathbf{r}_{h}\right)=C_{X} \psi_{e}\left(\mathbf{r}_{e}\right) \psi_{h}\left(\mathbf{r}_{h}\right) \exp \left[-\alpha_{X}\left|\mathbf{r}_{e}-\mathbf{r}_{h}\right|\right]$

where $\alpha_{X}$ is a variational parameter.

The calculation of the corresponding energies is carried out for the QD heterosystem $\mathrm{CdS} / \mathrm{SiO}_{2}$, the parameters of which are given in the Table.

Figure 1 shows the results of calculations of the energies of the ground states of the exciton and the every exciton-impurity complexes for different radii of the QD. It can be seen that the WannierMott exciton energy is close to the energy of the exciton-impurity complex $D^{+}-X$ for the entire region of the change of the $\mathrm{QD}$ radius $(10 \AA \leq$ $\leq a \leq 60 \AA$ ).

It is seen that the presence of impurities leads to a decrease in the electron-hole pair energy, as compared with the case of their absence. This means that, in the presence of such impurities, the creation of exciton-impurity complexes is more energyefficient. The possible existence of such complexes in the CdS QD was indicated in the experimental works $[10,13]$.

In order to compare the theoretical results with the experimental data, we show the energy of quantum transitions during luminescence of the CdS QD, which was experimentally determined in [10,13], in Fig. 1. Based on the calculations, we can conclude that the energies $E_{1}=3.05 \mathrm{eV}$ and $E_{2}=2.75 \mathrm{eV}$ can be interpreted as those corresponding to the electronhole transition in case of their recombination in the presence of a charged donor or in the absence of it. The transition energy $E_{3}=2.25 \mathrm{eV}$ can be related to the presence of a neutral acceptor, which forms the exciton complex $A^{0}-X$, in the QD. For the transition $E_{4}=1.95 \mathrm{eV}$, it is of importance to find a satisfactory theoretical explanation.

In order to determine the contribution of each of the impurity complexes to the optical parameters, the absorption coefficient of the heterosystem in the presence of various types of exciton-impurity complexes in the QDs is also calculated.

\section{Light Absorption \\ Coefficient of the Heterosystem with QDs}

Let the heterosystem be irradiated by a monochromatic linearly polarized light at the frequency

ISSN 2071-0186. Ukr. J. Phys. 2018. Vol. 63, No. 12 
$\omega=2 \pi c / \lambda$ and with weak intensity (insufficient for the manifestation of nonlinear effects). Accordingly, the absorption coefficient of a nanoheterosystem with QDs, which is due to interband direct transitions, is determined at low temperatures by the formula [16]:

$\alpha_{\mathrm{QD}}(\lambda)=\frac{A}{\hbar \frac{2 \pi}{\lambda}} \sum_{i, j}\left|\left\langle\psi_{i} \mid \psi_{j}\right\rangle\right|^{2} \delta\left(E_{j}-E_{i}-\hbar \omega(\lambda)\right)$,

where $A=\frac{2 \pi \hbar e^{2}}{m_{0} \varepsilon_{0} c} \frac{N}{n} E_{p}, e$ is the electron charge, $m_{0}$ is the free electron mass, $\varepsilon_{0}$ is the electric constant, $c$ is the speed of light, $N$ is the concentration of QDs, $n=\sqrt{\varepsilon}, \hbar \omega$ is the light quantum energy, $E_{p} \approx 23 \mathrm{eV}$ is Kane's matrix element [16], and $\psi_{i}$ and $\psi_{j}$ are the envelope wave functions of the initial $i$ and final $j$ states. In what follows, we consider the twolevel system: $E_{1}$ is the energy of the system provided that the electron is in the valence band, and $E_{2}=E_{1}+\hbar \omega$.

We consider the heterogeneous expansion of absorption bands, which is related to the dispersion of the dimensions of a QD in the matrix. In [17], it was shown that the account for such a dispersion determines the final half-width of the absorption band. Let the distribution of the QD dimensions be described by the Gauss function

$g(s, \bar{a}, a)=\frac{1}{s \sqrt{2 \pi}} \exp \left(-\frac{(a-\bar{a})^{2}}{2 s^{2}}\right)$,

where $a$ is the QD radius (variable), $s$ is the halfwidth of distribution (14), which is defined by the mean radius $\bar{a}$ and the value of $\sigma$ expressed in percentages: $s=\bar{a} \sigma / 100$. With refard for all the approximations described above, the absorption coefficient of a heterosystem with the QD takes the form:

$\alpha(\lambda)=B \lambda \int g(s, \bar{a}, a) I_{2,1}(a) \delta\left(E_{2}(a)-\right.$

$\left.-E_{1}(a)-\hbar \omega(\lambda)\right) d a$,

where

$I_{2,1}(a)=\left|\left\langle\psi_{2} \mid \psi_{1}\right\rangle\right|^{2}$

is the overlap integral, and $B=\frac{A}{2 \pi \hbar}$. In view of the properties of the delta-function, we get

$\alpha(\lambda)=B \lambda \int g(s, \bar{a}, a) I_{2,1}(a) \times$

ISSN 2071-0186. Ukr. J. Phys. 2018. Vol. 63, No. 12 $\times \sum_{n} \frac{\delta\left(a-a_{0, n}\right) d a}{\left|\frac{d}{d a}\left(E_{2}(a)-E_{1}(a)-\hbar \omega(\lambda)\right)\right|_{a=a_{0, n}}}$,

where $a_{0, n}$ are simple zeros of the function $F(a)=$ $=\left(E_{2}(a)-E_{1}(a)-\hbar \omega(\lambda)\right)$. Hence,

$\alpha(\lambda)=B \lambda \sum_{n} \frac{g\left(s, \bar{a}, a_{0, n}\right) I_{2,1}\left(a_{0, n}\right)}{\left|\frac{d}{d a}\left(E_{2}(a)-E_{1}(a)-\hbar \omega(\lambda)\right)\right|_{a=a_{0, n}}}$.

Now, we set specific $\psi_{1}$ and $\psi_{2}$ in (18). If there is no impurity in the $\mathrm{QD}$, and when an exciton is formed by the absorption of an electromagnetic wave, then $\psi_{1}=\delta\left(\mathbf{r}_{e}-\mathbf{r}_{h}\right)$ and $\psi_{2}=\psi_{X}\left(\mathbf{r}_{e}, \mathbf{r}_{h}\right)$. When there is the ion of a donor or acceptor impurity in the $\mathrm{QD}$ and when the light is absorbed, the complex $D^{+}-X$ or $A^{-}-X$ is formed. Then $\psi_{1}=$ $=\delta\left(\mathbf{r}_{e}-\mathbf{r}_{h}\right)$ and $\psi_{2}=\psi_{\left\{\begin{array}{l}D^{+}-X \\ A^{-}-X\end{array}\right\}}\left(\mathbf{r}_{e}, \mathbf{r}_{h}\right)$. Let a neutral donor (acceptor) impurity be in the $\mathrm{QD}$ and let, when light absorbed, a complex $D^{0}-X\left(A^{0}-X\right)$ be formed. Then $\psi_{1}=\psi_{\left\{\begin{array}{l}D\}, 1 \\ A\end{array}, 1\right.}\left(\mathbf{r}_{\left\{\begin{array}{l}e \\ h\end{array}\right\}, 1}\right) \delta\left(\mathbf{r}_{\left\{\begin{array}{l}h \\ e\end{array}\right\}}-\mathbf{r}_{\left\{\begin{array}{l}e \\ h\end{array}\right\}, 2}\right)$, $\psi_{2}=\psi_{\left\{\begin{array}{l}D-X \\ A-X\end{array}\right\}}\left(\mathbf{r}_{\left\{\begin{array}{l}h \\ e\end{array}\right\}}, \mathbf{r}_{\left\{\begin{array}{l}e \\ h\end{array}, 1,1\right.}, \mathbf{r}_{\left\{\begin{array}{l}e \\ h\end{array}, 2\right.}\right)$. The overlapping integrals were calculated for all these QD models, and the absorption coefficients were determined according to formula (18).

Figure 2 shows the plots of the wavelength dependence of the relative light absorption coefficient for the $\mathrm{CdS} / \mathrm{SiO}_{2}$ heterosystem.

It is seen that each of the above-described light absorption mechanisms corresponds to different values

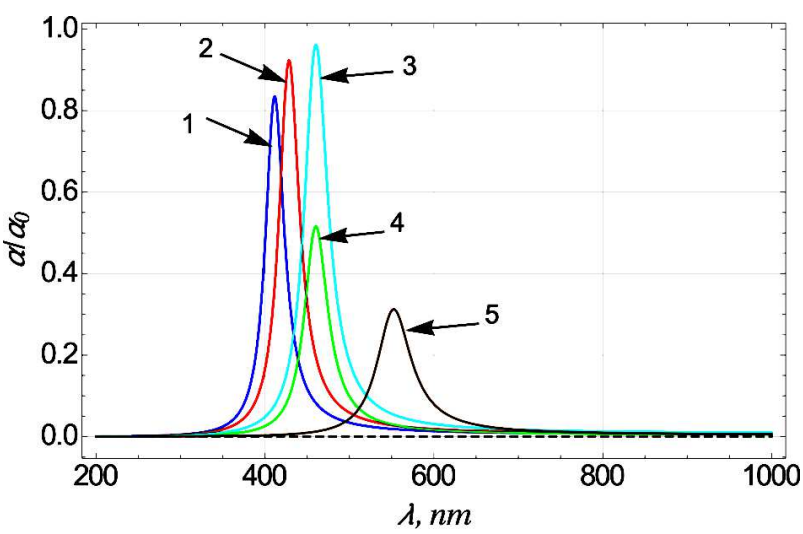

Fig. 2. Dependence of the relative absorption coefficient for each individual type of the exciton complex on the wavelength. Curve 1 corresponds to the exciton absorption $X, 2-D+-X$, $3-A^{-}-X, 4-D^{0}-X, 5-A^{0}-X$. Average radius of the QD is $17 \AA, \sigma=10 \%$ 


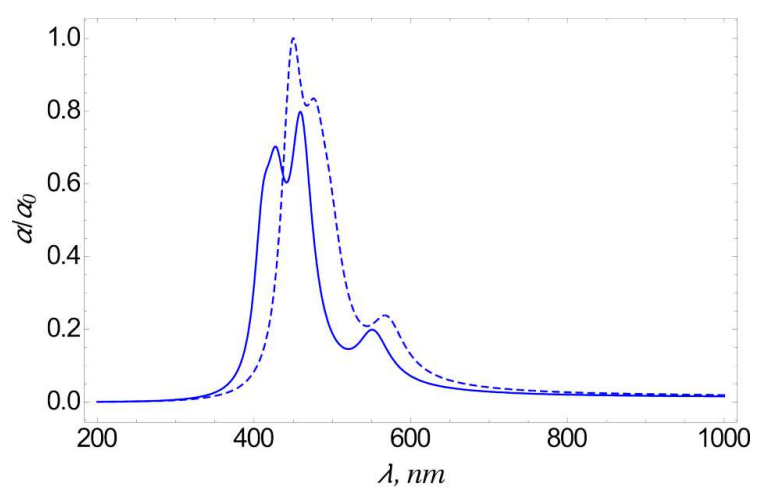

Fig. 3. Dependence of the relative absorption coefficient with regard for all the absorption mechanisms described above. The solid and dashed curves correspond to the average QD radii equal to 17 and $21.5 \AA$, respectively, $\sigma=10 \%$

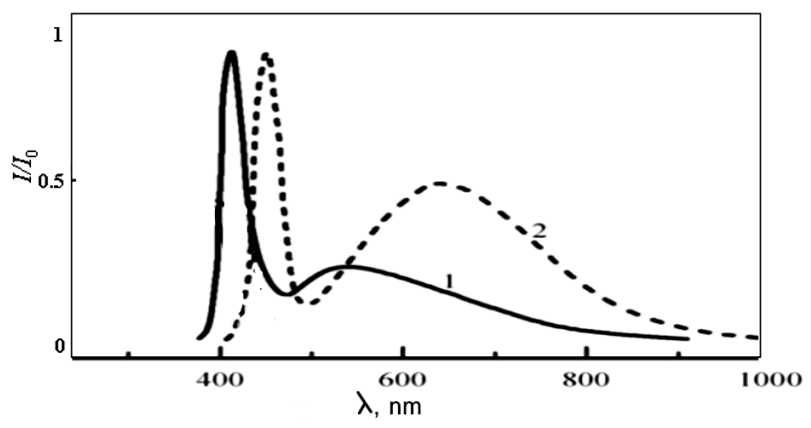

Fig. 4. Dependence of the relative luminescence intensity for CdS nanocrystals. The solid and dashed curves correspond to the QD average radii 17 and $21.5 \AA[10,13]$

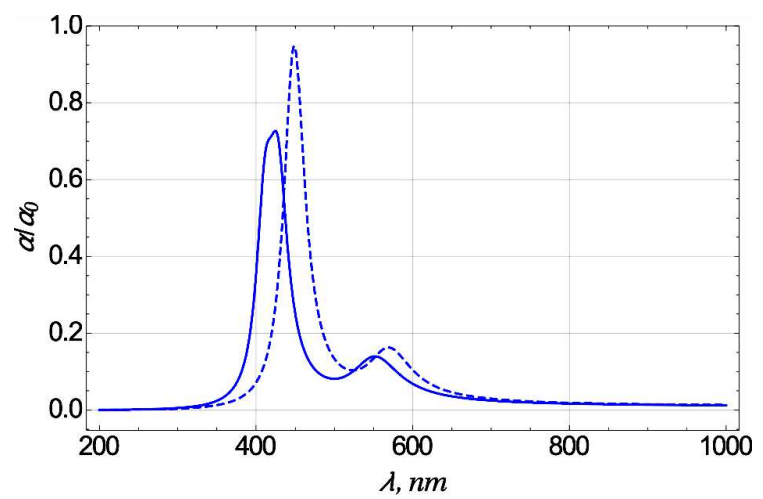

Fig. 5. Relative absorption coefficient of light for nanocrystals with an average radius of $17 \AA$ (solid) and $21.5 \AA$ (dashed); $\sigma=10 \%$

of absorption peaks and their positions on the scale of wavelengths. For an average QD radius $17 \AA$, the presence of impurities leads to the displacement of all absorption peaks toward long waves relative to the exciton band (curve 1 ). The absorption peaks due to the presence of a neutral impurity $D^{0}$ or $A^{0}$ are approximately two times smaller than the absorption peaks responsible for the presence of $D^{+}$or $A^{-}$ion impurity ions.

If we take into account that all the above-mentioned absorption mechanisms occur in the QD heterosystem, then the absorption coefficient will have the same form as in Fig. 3. The resulting graph is compared with the corresponding luminescence graphs of the experimental works [10,13] (Fig. 4).

If we compare the calculated values (Fig. 3) and the experimental ones (Fig. 4), then it is evident that not all of the types of impurity-exciton complexes mentioned above were obviously observed in the experiment. In this connection, we think that, in the experimental work dealing with the QD heterosystem, there are impurities of the acceptor type that interact with excitons. There are also pure homogeneous QDs, where the exciton transitions are observed. To compare experimental data, we calculated the absorption in the case of a pure exciton $X$ and an exciton that interacts with the neutral acceptor $A^{0}-X$. The results are presented in Fig. 5.

As one can see, we obtained a qualitative agreement of the energies and half-widths for long-wave bands and the quantitative agreement of these quantities for exciton bands. The main maxima on the experimental curves are due to the recombination of pure excitons, and the recombination with the participation of a neutral acceptor gives a contribution to the broad band. It should be noted that the luminescence causes a Stokes shift [17-19]. Experimentally, the luminescence maxima were observed at $435 \mathrm{~nm}$ (average radius $17 \AA$ ) and $480 \mathrm{~nm}$ (average radius $21.5 \AA$ ). The maxima of the main exciton absorption in our work for similar sizes correspond to $420 \mathrm{~nm}$ and $450 \mathrm{~nm}$. In other words, the experimental peaks of luminescence are shifted to the long-wave region in comparison with our absorption results of $15 \mathrm{~nm}$ and $30 \mathrm{~nm}$, respectively. The resulting energy differences are consistent with the Stokes shift data for QDs in CdS [13, 14, 18, 19].

As to the quantitative coincidence of the theory and experiment in the region of 550-650 nm, certain differences can be explained by the fact that the theory did not involve the surface defect states that could also contribute to a wide luminescence band. Along with this, there may be other causes (in particular, 
phonon origin), which lead to the obtaining of wide radiation bands of light.

\section{Conclusions}

Experimental works devoted to the study of the absorption and luminescence spectra of impurity CdS nanocrystals [11-13] put a number of unresolved problems before the researchers. In the proposed theoretical work, the influence of impurity atoms and their ions of the donor and acceptor types on the exciton excitation energy is studied. Thus, we consider five types of the QD excitation: with the formation of the Wannier-Mott exciton and four types of excitonimpurity complexes $\left(D^{+}-X, D^{0}-X, A^{-}-X\right.$, $\left.A^{0}-X\right)$.

The calculations have shown that, for the mean CdS QD radii $a=17$ Aand $21.5 \AA$, which appear in [13], the energies of the exciton formation and the exciton-impurity complex with the donor ion $\left(E_{D^{+-X}}\right)$ are quite close in magnitude. The energies of the $D^{0}-X$ and $A^{-}-X$ complexes for the same QD radii are similar as well. For these energies, the condition $E_{D^{0}-X} \approx E_{A^{-}-X}<E_{X} \approx E_{D^{+-X}}$ holds. The energy of the formation of the complex $A^{0}-X$ is the smallest.

The dependence of the total absorption coefficient of light on the wavelength for a heterosystem with such types of electron excitation shows that the main absorption band is characterized by two maxima ("humps"). It is formed by the quantum transitions of an electron with the formation of $X, D^{+}-X$, $D^{0}-X$, and $A-X$. The long-wave wing of this band appears during the formation of the complex $A^{0}-X$. It is worth noting that the wavelength of light, at which the maximum absorption coefficient is realized at $a=17 \AA$, is close to the corresponding wavelength of the maximum of the luminescence intensity in work [13]. For QDs with an average radius of $21.5 \AA$, the discrepancy between theory and experiment is greater. This problem will be discussed in our next work.

1. C.C. Yang, L.C. Liu, S.H. Chang. Eigenstates and fine structure of a hydrogenic impurity in a spherical quantum dot. Phys. Rev. B 58, 1954 (1998).

2. V. Holovatsky, I. Bernik, O. Voitsekhivska. Oscillator strengths of quantum transition in spherical quantum $\operatorname{dot} \mathrm{GaAs} / \mathrm{Al}_{x} \mathrm{Ga}_{1}-\mathrm{As} / \mathrm{GaAs} / \mathrm{Al}_{x} \mathrm{Ga}_{1-x}$ As with on-center donor impurity. Acta Phys. Pol. A 125, (2014).
3. V. Holovatsky, O. Makhanets, O. Voitsekhivska. Oscillator strengths of electron quantum transitions in spherical nanosystems with donor impurity in the center. Physica E: Low-Dimensional Systems and Nanostructures 41, 1522 (2009).

4. V.I. Boichuk, I.V. Bilynskyi, R.Ya. Leshko, L.M. Turyanska. The effect of the polarization charges on the optical properties of a spherical quantum dot with an off-central hydrogenic impurity. Physica E: Low-Dimensional Systems and Nanostructures 44, 476 (2011).

5. V.I. Boichuk, I.V. Bilynskyi, R.Ya. Leshko, L.M. Turyanska. Optical properties of a spherical quantum dot with two ions of hydrogenic impurity. Physica E: Low-Dimensional Systems and Nanostructures 54, 281 (2013).

6. V.I. Boichuk, R.Ya. Leshko, I.V. Bilynskyi, L.M. Turyanska. Off-central acceptor impurity in a spherical quantum dot. Cond. Matt. Phys. 15, 33702 (2012).

7. V.I. Boichuk, R.Ya. Leshko, D.S. Karpyn. Analysis of the effect of polarization traps and shallow impurities on the interlevel light absorption of quantum dots. Cond. Matt. Phys. 20, 43704 (2017).

8. V.A. Holovatsky, I.B. Frankiv. Oscillator strength of quantum transition in multi-shell quantum dots with impurity. J. Optoelectr. Adv. Mater. 15, 88 (2013).

9. G. Rezaei, M.R.K. Vahdani, B. Vaseghi. Nonlinear optical properties of a hydrogenic impurity in an ellipsoidal finite potential quantum dot. Current Appl. Phys. 11, 176 (2011).

10. A. Hässelbarth, A. Eychmüller, H. Weller. Detection of shallow electron traps in quantum sized CdS by fluorescence quenching experiments. Chem. Phys. Lett. 203, 271 (1993).

11. D.V. Korbutyak, S.V. Tokarev, S.I. Budzulyak, A.O. Kuryk, V.P. Klad'ko, Yu.O. Polishchuk, O.M. Shevchuk, G.A. Il'chuk, V.S. Tokarev. Optical and structural defect characteristics of nanocrystals CdS: $\mathrm{Cu}$ and CdS:Zn synthesized in polymeric matrices. Fiz. Khim. Tv. Tila 14, 222 (2013).

12. A.I. Savchuk, I.D. Stolyarchuk, T.A. Savchuk, M.M. Smolinsky, O.A. Shporta, L.M. Shynkura. Monitoring of incorporation of magnetic ions into II-VI semiconductor nanocrystals by optical and magneto-optical spectroscopy. Thin Solid Films 541, 79 (2013).

13. D.V. Korbutyak, O.V. Kovalenko, S.I. Budzulyak et al. Light-emitting properties of quantum dots in semiconductor compounds $\mathrm{A}_{2} \mathrm{~B}_{6}$. Ukr. Fiz. Zh. Oglyady 7, 48 (2012).

14. D.F. Fanga, Z.M. Zhangb, Z.P. Wangb, Z.J. Dinga. Photoluminescence of $\mathrm{CdS} / \mathrm{ZnS}$ core/shell quantum dots. Physics Procedia 32, 920 (2012).

15. A. Medvid, V.G. Litovchenko, D. Korbutjak, S.G. Krilyuk, L.L. Fedorenko, Y. Hatanaka. Influence of laser radiation 
on photoluminescence of CdTe Radiation Measurements 33, 725 (2001).

16. G. Bastard. Wave Mechanics Applied to Semiconductor Heterostructures (Les Editions de Physique, 1988).

17. I.M. Kupchak, D.V. Korbutyak, S.M. Kalytchuk. The Stokes shift in quantum dots in CdTe. Zh. Fiz. Doslid. 14, 2701 (2010)

18. Al.L. Efros, M. Rosen. Band-edge exciton in quantum dots of semiconductors with a degenerate valence band: Dark and bright exciton states Phys. Rev. B 54, 4843 (1996).

19. V.I. Boichuk, I.V. Bilynskyi, I.O. Shakleina, I. Kogoutiouk. Dielectric mismatch in finite barrier cubic quantum dots. Physica E: Low-Dimensional Systems and Nanostructures 43, 161 (2010).

Received 03.04.18
В.І. Бойчук, Р.Я. Лешко, Д.С. Карпин

ВПЛИВ МІЛКИХ ДОМШШОК НА СПЕКТР ПОГЛИНАННЯ СВІТЛА НАНОКРИСТАЛАМИ СdS

$\mathrm{P}$ е $з$ ю м е

У роботі обчислено енергії квантових переходів екситоннодомішкових станів у гетеросистемі з нанокристалами. Визначено енергї цих переходів та проаналізовано спектри поглинання, що пов'язані із зазначеними переходами. Якісно показано, що широкі смуги люмінесценції у червоній області пов'язані з домішковими акцепторними станами, а високі вузькі у фіолетовій області - $з$ чистими екситонними станами та екситонними станами, що взаємодіють з іоном донора. Отримано задовільне кількісне узгодження наших обчислень з експериментальними даними для високоенергетичних смуг люмінесценції. 